\title{
Genetic testing and insurance in Australia
}

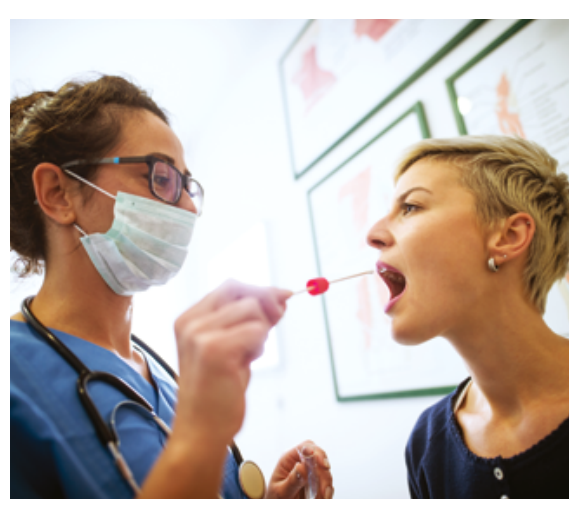

Margaret Otlowski, Jane Tiller, Kristine Barlow-Stewart, Paul Lacaze

\section{Background}

Genetic testing offers great benefit for the diagnosis of genetic conditions and to identify and manage risk for conditions such as familial breast cancer. However, potential personal insurance implications exist for some patients who undergo genetic testing in Australia. Currently, insurance companies offering risk-rated products such as life insurance can use genetic test results to discriminate, which may adversely affect applicants' ability to secure a policy. Many comparable countries have banned or restricted life insurers' use of genetic results, while Australia still permits it. However, the industry proposes to introduce a moratorium limiting the use of genetic results for life insurance underwriting in mid-2019.

\section{Objective}

This paper explores the implications of genetic testing for risk-rated insurance for the general practice workforce in Australia.

\section{Discussion}

Advancements in technology and decreasing costs have resulted in rapid expansion in genetic/genomic testing, which is set to become part of mainstream healthcare. General practitioners (GPs) in Australia will have an increasingly significant part to play in the expanded use of this testing, and it is therefore important that GPs are aware of these issues.
GENETIC TESTING - which refers to testing of single genes, one at a time - can be of great benefit for diagnosis of genetic conditions as well as for understanding and managing risk for those with a family history of conditions such as familial breast cancer. With decreasing costs and increased access, genetic testing is also broadening to genomic testing - the ability to test the entire genome, which comprises all the DNA in an individual's cells. However, there are legal and ethical implications arising, particularly with predictive genetic testing - that is, testing to ascertain whether a person has inherited a gene variant (mutation) that predisposes them to a genetic condition. An important dimension of this relates to the implications of genetic testing for risk-rated products such as life insurance-specifically the fact that a positive genetic test result may adversely affect a person's ability to secure a policy. Importantly, this does not apply to private health insurance in Australia, which is not risk-rated (Box 1). As general practitioners (GPs) in Australia will have an

\section{Box 1. A note on private health insurance}

It is important to note that, in Australia, private health insurance is not affected by genetic test results - the Private Health Insurance Act 2007 (Cwlth) prohibits discrimination by health insurers, and private health insurance is not underwritten. increasingly important part to play in the expanded rollout of genetic and genomic testing, GPs interacting with patients who may be considering genetic or genomic testing must be aware of these issues.

\section{Changing Australian landscape - from genetics to mainstreaming of genomics}

In recent years, genetic testing has advanced from single gene testing offered in specialist services to increasingly accessible genomic testing involving massively parallel sequencing of exomes or even whole genome sequencing. This 'next generation sequencing' generates vast amounts of information that can be difficult to interpret and presents greater risk of misuse. Such testing is also available 'direct-to-consumer' (DTC), whereby consumers access testing online and receive information directly, without any counselling or clinical guidance and variable quality control. They may approach their GPs for assistance in interpreting the results and the implications.

These developments raise workforce issues for health professionals, including GPs, who require support to assist them to provide best practice care to their patients. GPs can currently request a range of genetic/genomic tests, ${ }^{1}$ and all Australian states and territories have specialist genetic risk assessment, testing and counselling services. ${ }^{1}$ However, 
these services are becoming strained, with the growing uptake of genomics creating significant workforce challenges nationally. ${ }^{2}$

The Australian National Health Genomics Policy Framework 2018-2021, which aims to integrate genomics into national healthcare through significant government investment, has identified a role for the broader health workforce in the delivery of clinical genomics. This signals a clear expectation that issues generated by genetic or genomic testing will increasingly arise in general practice, and highlights the importance of providing health professionals with the resources to respond.

Significantly, risks and barriers associated with these developments have also been recognised by the Framework: ${ }^{2}$

\section{While the application of genomic} knowledge to health care has the potential to transform the health system, it also presents risks to individuals and society, particularly those related to privacy, security and storage of data, and the potential for genomic discrimination.

These issues have been identified in the Framework as a priority area for action.

Current gaps in GP training in and understanding of genetics have been acknowledged ${ }^{3}$ and may have implications for patients - for example, ensuring informed consent relies on GPs' understanding of genetic testing and its implications. ${ }^{4}$

\section{Use of genetic test information in underwriting insurance in Australia}

Currently in Australia, life insurance companies can legally require applicants to disclose all genetic test results and use this information in underwriting (risk rating). This includes not only clinical genetic testing undertaken by accredited laboratories, but also genetic results obtained through participation in research and DTC testing, regardless of the fact that these may not meet scientific and medical requirements associated with clinical tests.

Life insurance contracts are subject to a stringent duty of disclosure under the Insurance Contracts Act 1984 (Cwlth); if it is established that relevant information was withheld, the contract may later be invalidated.

Life insurance products - including cover for death, trauma and income protection - are guaranteed renewable: once a policy is secured, and providing an individual continues to pay their premiums, there is no requirement to disclose any change of circumstances (eg if they subsequently undertook genetic testing and found out about predisposition to a genetic disease). However, this only applies to the insurance product initially secured; fresh disclosure obligations apply to any change or increase to the cover. Therefore, patients must be made aware during pre-test counselling of the potential life insurance implications of obtaining genetic test results. Patients may want to consider securing their insurance needs before undergoing genetic testing. This is both legally and ethically defensible, because the patient does not know more than the life insurance company prior to testing, and is required to disclose relevant family history of disease in any event.

Note that sickness and accident insurance products are annually renewable, so any change in information must be disclosed every year. Travel insurance is also risk-rated, but a positive predictive genetic test result in an asymptomatic person should not have an adverse effect.

Using predictive genetic test information in insurance underwriting essentially involves discriminating on the basis of genetic status - the fact that testing has indicated an individual is predisposed to developing a condition in future. This is currently allowed because insurers have an exemption from the broad discrimination protections in the Disability Discrimination Act 1992 (Cwlth). Under that Act, discrimination that would otherwise be unlawful is justified if it is based on actuarial or statistical data on which it is reasonable to rely, having regard to the matter of the data and other relevant factors; or where no such actuarial or statistical data are available and cannot reasonably be obtained, the discrimination is reasonable having regard to any other relevant factors.
While it is the insurer's responsibility to show it has a valid basis for discrimination under this exemption, in reality it is difficult for an individual applicant to challenge an adverse insurance decision. In practice, insurers often do not give full details of the reasons for their decision to decline insurance, charge higher premiums or impose non-standard terms. Currently, the policy pertaining to the use of genetic test results in life insurance in Australia is developed by the Financial Services Council (FSC), with minimal or no government oversight. This represents a conflicted model of industry self-regulation, with limited transparency to consumers. Further, there is currently no easy cost-free process for individuals to independently challenge adverse underwriting decisions.

Given the lack of statistically robust actuarial or statistical data for many genes and genetic conditions, we query how often discrimination on the basis of a genetic test result can be legally justified under this exemption. The concern is that where a deterministic approach is taken to genetics, genetic test information may be credited with greater probative value than it warrants, undermining the Disability Discrimination Act consumer protections because the discrimination goes beyond what is justified.

\section{Concerns with allowing insurers access to genetic test information for underwriting}

A growing body of research shows the occurrence of unlawful genetic discrimination, whereby insurance applications are declined or offered on non-standard terms (eg loaded premiums, exclusions applied) without adequate justification or explanation provided to the consumer. ${ }^{5-7}$ Cases include failure by the life insurance company to take account of preventive measures such as prophylactic surgery, contrary to the industry's own guidelines. ${ }^{6,8}$ While cases of unlawful discrimination are clearly concerning, the very existence of such cases and the potential for such discrimination has created insurance fears that are deterring the uptake of genetic testing and 
participation in medical research., ${ }^{9,10}$ These fears are reinforced every time a person is counselled in relation to predictive genetic testing and the potential risks as part of the informed consent process for clinical testing or for genetic research studies. This fear and the resulting deterrence represents a real barrier to the implementation of the goal of mainstreaming genomics into healthcare.

The limitations of the status quo were highlighted some years ago when the Australian Law Reform Commission recommended that only approved genetic tests should be available for use in life insurance underwriting, having regard to their scientific reliability, actuarial relevance and reasonableness. ${ }^{11}$ Regrettably, this recommendation was never implemented, as the government entrusted its implementation to the life insurance industry, without accountability. This highlights limitations inherent with a self-regulated industry, without government oversight, as shown by significant erosion of the consumer protections in the current iteration of the FSC genetic testing policy. ${ }^{12}$

The stance currently taken in Australia is in marked contrast to the position taken by many comparable overseas jurisdictions, which have recognised the need for greater consumer protection. This includes the UK, where a moratorium on the use of genetic test information has been in effect since 2001, many European countries ${ }^{13}$ and more recently Canada $^{14}$, which have legislated to prohibit life insurers from using genetic test information.

Calls for reform of the law in Australia have been mounting, as reflected in the Human Genetics Society of Australasia's most recent Position Statement on genetic testing and personal insurance products (February 2018) and through the Australian Genetic Non-Discrimination Working Group's submission to the Parliamentary Inquiry into the life insurance industry. ${ }^{15}$ In its March 2018 report, that Inquiry recommended that a moratorium be introduced in the use of genetic test information for underwriting in life insurance in Australia. ${ }^{16}$ The problem of genetic discrimination was seen as likely to become even more significant in the near future in light of continual developments in the area of genetics, as well as cost reductions.

Implementation of the Inquiry's recommendations will be essential for reassuring patients and their families, clinicians and research participants that uptake of genetic or genomic testing will not have negative implications for future life insurance applications. This is a critical step towards the goal of mainstreaming genomics within healthcare in order to realise its full potential. In a positive development, the Financial Services Council has announced plans to introduce a moratorium limiting the use by life insurers of genetic test information commencing July 2019. Any reforms will need to be augmented by education and public awareness campaigns, including information for health professionals to optimally equip them to perform their roles.

\section{Implications for general practice}

While the law requires that an applicant for underwritten insurance disclose all genetic test results (obtained clinically, through research or DTC), GPs must be alert to the insurance implications of genetic testing.

The National Health Genomics Policy

Framework: ${ }^{2}$

- emphasises that for genomic knowledge to be integrated into the health system, it is critical that the broader health workforce develops an understanding of the application of genomics to healthcare

- recognises the limited workforce training and education opportunities currently available outside of the specialist clinical genomics services to ensure genomic literacy and capability to deliver high-quality and safe clinical genomic services by the broader health workforce

- acknowledges the potential for genetic discrimination as a barrier to the effective integration of genomics into healthcare.

Given the fast-moving nature of genetics, it is important that GPs and genetics service providers (clinical geneticists, genetics specialists and genetic counsellors) develop strong relationships to enable advice and facilitate appropriate referral. ${ }^{17}$

Research has found that many Australian GPs do not feel confident in providing advice or counselling about genetic testing, ${ }^{18}$ particularly where advice is sought about personal genomic test results obtained from online DTC companies. ${ }^{19}$ The National Health and Medical Research Council (NHMRC) has developed a guidance document for health professionals regarding the limitations and risks associated with DTC tests ${ }^{20}$ as well as a consumer resource urging careful consideration of the insurance and privacy implications. ${ }^{21}$ It has been suggested that GPs are well placed to help patients understand the evidence base for DTC genomic testing, including developing healthy scepticism about extravagant claims, and to ensure patients consider life insurance implications of genetic testing, especially if they are hoping to change or apply for new disability or life insurance policies. ${ }^{22}$

There is growing recognition of the need to support GPs with more education and training in this area, including a recent call from the Australian Medical Association in its submission to the insurance Inquiry. ${ }^{23}$ There have been ongoing efforts to address this need by the $\mathrm{NHMRC}^{3}$ and The Royal Australian College of General Practitioners ${ }^{24}$ through the development of resources for GPs about genetic and genomic testing. The Centre for Genetics Education has also been proactive in providing resources, including a Fact Sheet on life insurance products and genetic testing in Australia. ${ }^{25}$

\section{Conclusion}

Given the increasing availability of genetic testing outside of the clinical context, it is important that GPs have up-to-date knowledge and are equipped to assist patients by being informed about the availability of genetic tests and information relevant for patients to take into account. Currently, life insurers are entitled to use genetic test information for underwriting; however, there are 
now real prospects for change with the moratorium proposed by the Financial Services Council.

\section{Authors}

Margaret Otlowski LLB(Hons), PhD, Centre for Law and Genetics, Faculty of Law, University of Tasmania, Hobart, Tas. margaret.otlowski@utas.edu.au

Jane Tiller BSc/LLB (Hons), Master of Genetic Counselling, Department of Epidemiology and Preventive Medicine, School of Public Health and Preventive Medicine, Monash University, Vic Kristine Barlow-Stewart BSc, PhD, FHGSA (Gen Couns), Director Master of Genetic Counselling Program, Northern Clinical School, Faculty of Medicine and Health, University of Sydney, NSW

Paul Lacaze BSc, MSc, PhD, Department of Epidemiology and Preventive Medicine, School of Public Health and Preventive Medicine, Monash University, Vic

Competing interests: The authors are all members of the Australian Genetic Non-Discrimination Group. JT and KBS report providing consulting services to genetic testing companies.

Funding: None.

Provenance and peer review: Commissioned, externally peer reviewed.

\section{References}

1. Blashki G, Metcalfe S, Emery J. Genetics in general practice. Aust Fam Physician 2014;43:428-31.

2. Australian Health Ministers' Advisory Council. National Health Genomics Policy Framework 2018-2021. Canberra: DoH, 2017. Available at https://trove.nla.gov.au/work/ 229838587?selectedversion=NBD61494036 [Accessed 18 September 2018].

3. National Health and Medical Research Council. Medical genetic testing: Information for Health Professionals. Canberra: NHMRC, 2010. Available at https://www.nhmrc.gov.au/guidelinespublications/e99 [Accessed 18 September 2018].

4. Morgan S, McLeod D, Kidd A, Langford B. Genetic testing in New Zealand: The role of the general practitioner. The New Zealand Medical Journal 117(1206):U1178.

5. Keogh L, Otlowski M. Life insurance and genetic test results: A mutation carrier's fight to achieve full cover. Med J Aust 2013 ;199(5):363-66.

6. Barlow-Stewart K, Taylor SD, Treloar SA, Stranger M, Otlowski M. Verification of consumers' experiences and perceptions of genetic discrimination and its impact on utilization of genetic testing. Genet Med 2009;11(3):193-201. doi: 10.1097/GIM.0b013e318194ee75.

7. Barlow-Stewart K, Liepins M, Doble A, Otlowski M. How are genetic test results being used by Australian life insurers? Eur J Hum Genet 2018;26(9):1248-56. doi: 10.1038/s41431-018-0198-z.

8. Financial Services Council. Genetic testing policy. Standard no. 11. Sydney: FSC, 2016. Available at www.fsc.org.au/resources/standards/11sgenetic-testing-policy-final.pdf [Accessed 18 September 2018].

9. Keogh LA, Niven $H$, Rutstein A, Flander L, Gaff C, Jenkins M. Choosing not to undergo predictive genetic testing for hereditary colorectal cancer syndromes: Expanding ou understanding of decliners and declining. J Behav Med 2017;40(4):583-94. doi: 10.1007/ s10865-016-9820-0.
10. Keogh LA, van Vliet CM, Studdert DM, et al. Is uptake of genetic testing for colorectal cancer influenced by knowledge of insurance implications? Med J Aust 2009;191(5):255-58.

11. Australian Law Reform Commission. Essentially yours: The protection of human genetic information in Australia. Sydney: ALRC, 2013. Available at www.alrc.gov.au/publications/report96 [Accessed 18 September 2018].

12. Newson AJ, Tiller J, Keogh LA, Otlowski M, Lacaze P. Genetics and insurance in Australia: Concerns around a self-regulated industry. Public Health Genomics 2017;20(4):247-56. doi: 10.1159/000481450.

13. Otlowski M, Taylor S, Bombard Y. Genetic discrimination: International perspectives. Annu Rev Genomics Hum Genet 2012:13:433-54. doi: 10.1146/annurev-genom-090711-163800.

14. Tiller J, Otlowski M, Lacaze P. Should Australia ban the use of genetic test results in life insurance? Front Public Health 2017;5:330. doi: 10.3389/fpubh.2017.00330.

15. Australian Genetic Non-Discrimination Working Group. Submission regarding inquiry into the life insurance industry. Submission no. 60. Available at www.aph.gov.au/Parliamentary_Business/ Committees/Joint/Corporations_and_Financial Services/Lifelnsurance/Submissions [Accessed 21 January 2019].

16. Parliamentary Joint Committee on Corporations and Financial Services. Inquiry into the life insurance industry. Canberra: Parliament of Australia, 2018. www.aph.gov. au/Parliamentary_Business/Committees/ Joint/Corporations and Financial Services/ Lifelnsurance [Accessed 18 September 2018].

17. Burke W, Emery J. Genetics education for primarycare providers. Nat Rev Genet 2002;3(7):561-66.

18. Metcalfe S, Hurworth R, Newstead J, Robins R. Needs assessment study of genetics education for general practitioners in Australia. Genet Med 2002;4(2):71-77.

19. Brett G, Metcalf S, Amor DJ, Halliday JL. An exploration of genetic health professionals' experience with direct-to consumer genetic testing in their clinical practice. Eur J Hum Genet 2012;20(8):825-30. doi: 10.1038/ejhg.2012.13.

20. National Health and Medical Research Council. Discussing direct-to-consumer genetic DNA testing with patients: $A$ short guide for health professionals. Canberra: NHMRC, 2013. Available at https://nhmrc.gov.au/sites/default/files/ documents/attachments/Discussing\%20directto-consumer-genetic-dna-testing.pdf [Accessed 21 January 2019].

21. National Health and Medical Research Council. Understanding direct-to-consumer DNA testing: An information resource for consumers. Canberra: NHMRC, 2014. https://nhmrc.gov. au/sites/default/files/documents/reports/ direct-consumer-genetic-testing.pdf [Accessed 21 January 2019].

22. Hendrie D. What GPs need to know about the rising popularity of personal genomic testing. newsGP. 23 April 2018. Available at www.racgp. org.au/newsGP/Clinical/What-GPs-need-toknow-about-the-rising-popularity [Accessed 28 August 2018].

23. Moy C. Evidence to the Inquiry into the life insurance industry. Australian Medical Association. 10 October 2017. Available at: https://ama.com.au/ausmed/ama-evidenceinquiry-life-insurance-industry [Accessed 28 August 2018)
24. The Royal Australian College of General Practitioners. Genomics in general practice. East Melbourne, Vic: RACGP, 2018. Available at www. racgp.org.au/your-practice/guidelines/genomics/ [Accessed 18 September 2018].

25. Centre for Genetics Education. Fact Sheet 20: Life insurance products and genetic testing in Australia. NSW: Centre for Genetics Education, 2018. Available at www.genetics.edu.au/ publications-and-resources/facts-sheets/ fact-sheet-20-life-insurance-products-andgenetic-testing-in-australia [Accessed 21 January 2019]. 